\title{
Front Matter: Volume 9232
}

, "Front Matter: Volume 9232," Proc. SPIE 9232, International Conference on Optical Particle Characterization (OPC 2014), 923201 (11 August 2014); doi: 10.1117/12.2077312

SPIE Event: International Conference on Optical Particle Characterization (OPC SPIE. 2014), 2014, Tokyo, Japan 


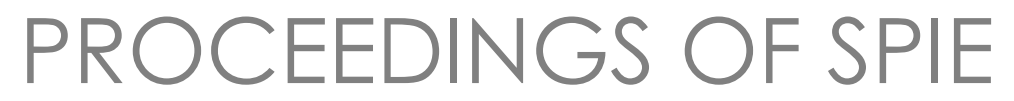

\title{
International Conference on Optical Particle Characterization (OPC 2014)
}

\author{
Nobuhiro Aya \\ Norihiko Iki \\ Tsutomu Shimura \\ Tomohiro Shirai \\ Editors
}

10-14 March 2014

Tokyo, Japan

Hosted by

National Institute of Advanced Industrial Science and Technology (AIST) (Japan)

Published by

SPIE 
The papers included in this volume were part of the technical conference cited on the cover and title page. Papers were selected and subject to review by the editors and conference program committee. Some conference presentations may not be available for publication. The papers published in these proceedings reflect the work and thoughts of the authors and are published herein as submitted. The publisher is not responsible for the validity of the information or for any outcomes resulting from reliance thereon.

Please use the following format to cite material from this book:

Author(s), "Title of Paper," in International Conference on Optical Particle Characterization (OPC 2014), edited by Nobuhiro Aya, Norihiko Iki, Tsutomu Shimura, Tomohiro Shirai, Proceedings of SPIE Vol. 9232 (SPIE, Bellingham, WA, 2014) Article CID Number.

ISSN: 0277-786X

ISBN: 9781628412864

Published by

SPIE

P.O. Box 10, Bellingham, Washington 98227-0010 USA

Telephone +1 3606763290 (Pacific Time) · Fax +1 3606471445

SPIE.org

Copyright @ 2014, Society of Photo-Optical Instrumentation Engineers.

Copying of material in this book for internal or personal use, or for the internal or personal use of specific clients, beyond the fair use provisions granted by the U.S. Copyright Law is authorized by SPIE subject to payment of copying fees. The Transactional Reporting Service base fee for this volume is $\$ 18.00$ per article (or portion thereof), which should be paid directly to the Copyright Clearance Center (CCC), 222 Rosewood Drive, Danvers, MA 01923. Payment may also be made electronically through CCC Online at copyright.com. Other copying for republication, resale, advertising or promotion, or any form of systematic or multiple reproduction of any material in this book is prohibited except with permission in writing from the publisher. The CCC fee code is 0277-786X/14/\$18.00.

Printed in the United States of America.

Publication of record for individual papers is online in the SPIE Digital Library.

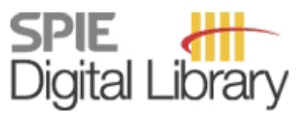

SPIEDigitalLibrary.org

Paper Numbering: Proceedings of SPIE follow an e-First publication model, with papers published first online and then in print and on CD-ROM. Papers are published as they are submitted and meet publication criteria. A unique, consistent, permanent citation identifier (CID) number is assigned to each article at the time of the first publication. Utilization of CIDs allows articles to be fully citable as soon as they are published online, and connects the same identifier to all online, print, and electronic versions of the publication. SPIE uses a six-digit CID article numbering system in which:

- The first four digits correspond to the SPIE volume number.

- The last two digits indicate publication order within the volume using a Base 36 numbering

system employing both numerals and letters. These two-number sets start with 00, 01, 02, 03, 04, 05, 06, 07, 08, 09, 0A, 0B ... 0Z, followed by 10-1Z, 20-2Z, etc.

The CID Number appears on each page of the manuscript. The complete citation is used on the first page, and an abbreviated version on subsequent pages. Numbers in the index correspond to the last two digits of the six-digit CID Number. 


\title{
Contents
}

\author{
ix Conference Committee \\ xiii Introduction
}

\section{INVITED LECTURE}

923202 A review on laser diagnostics on atomization and evaporation of liquid fuel (Invited Paper) [9232-31]

Y. Zhang, S. Li, B. Lin, Shanghai Jiao Tong Univ. (China); Y. Liu, J. WU, B. Xu, Henan Univ. of Science and Technology (China)

923203 Charactrisation of particle assemblies by 3D cross correlation light scattering and diffusing wave spectroscopy (Invited Paper) [9232-501]

F. Scheffold, Univ. of Fribourg (Switzerland)

NOVEL THEORETICAL METHODS

923204 A numerical evaluation of iterative solvers for the solution of static light scattering problems [9232-44]

H. Sugasawa, M. Umezawa, HORIBA Ltd. (Japan); K. Park, HORIBA Instruments Inc. (United States)

923205 Estimation of equivalence ratio distribution in diesel spray using a computational fluid dynamics [9232-24]

Y. Suzuki, T. Tsujimura, National Institute of Advanced Industrial Science and Technology (Japan); J. Kusaka, Waseda Univ. (Japan)

923206 Hybrid Mie-MCML Monte Carlo simulation of light propagation in skin layers [9232-28] Y. Kawai, T. Iwai, Tokyo Univ. of Agriculture and Technology (Japan)

923207 Optical caustics associated with the primary and the secondary rainbows of oblate droplets [9232-14]

H. YU, Univ. of Shanghai for Science and Technology (China) and Technische Univ. Darmstadt (Germany); J. Shen, Univ. of Shanghai for Science and Technology (China);

C. Tropea, Technische Univ. Darmstadt (Germany)

923208 Scattering of electromagnetic radiation based on numerical calculation of the T-matrix through its integral representation [9232-15]

U. Tricoli, K. Pfeilsticker, Univ. of Heidelberg (Germany) 
923209 Laser-diffraction based drop-sizing system using image sensor [9232-19]

T. Suzuki, K. Harase, Toyohashi Univ. of Technology (Japan)

$92320 \mathrm{~A}$ Measurement of vapor/liquid distributions in a binary-component fuel spray using laser imaging of droplet scattering and vapor absorption [9232-25]

S. Li, Y. Zhang, S. WU, Shanghai Jiao Tong Univ. (China); B. XU, Henan Univ. of Science and Technology (China)

$9232 \mathrm{OB} \quad$ Particulate morphology of waste cooking oil biodiesel and diesel in a heavy duty diesel engine [9232-16]

J. Hwang, KAIST (Korea, Republic of); Y. Jung, Sandia National Labs. (United States);

C. Bae, KAIST (Korea, Republic of)

9232 OC PTV analysis of the entrained air into the diesel spray at high-pressure injection [9232-22] N. Toda, H. Yamashita, Nippon Soken, Inc. (Japan); M. Mashida, DENSO Corp. (Japan)

\section{DROPLETS}

9232 OD Convection and surface tension profiles for aqueous droplet under microwave radiation [9232-9]

Y. Kanazawa, M. Asada, Y. Asakuma, I. Honda, Univ. of Hyogo (Japan); C. Phan,

H. Parmar, V. Pareek, Curtin Univ. (Australia); G. Evans, Univ. of Newcastle (Australia)

9232 OE Detection and evaluation of droplet and bubble fringe patterns in images of planar interferometric measurement techniques using the wavelet transform [9232-47] Y. Hardalupas, A. P. Taylor, Imperial College London (United Kingdom); K. Zarogoulidis, Imperial College London (United Kingdom) and Keio Univ. (Japan)

9232 OF In-situ observation of convection in droplet under microwave radiation by PIV [9232-12] M. Asada, Y. Kanazawa, Y. Asakuma, I. Honda, Univ. of Hyogo (Japan); C. Phan, H. Parmar, V. Pareek, Curtin Univ. (Australia); G. Evans, The Univ. of Newcastle (Australia)

9232 OG Micro-explosion of compound drops [9232-18]

C. Chen, T. Lin, National Cheng Kung Univ. (Taiwan)

$9232 \mathrm{OH}$ The time-shift technique for measurement size of non-transparent spherical particles [9232-6]

W. Schäfer, C. Tropea, Technische Univ. Darmstadt (Germany) and AOM-Systems GmbH (Germany)

\section{NANOPARTICLES}

9232 ol High-sensitivity low-coherence dynamic light scattering and particle sizing for nanoparticles (II): SM-fiber probe system applied to dense particle suspensions [9232-23] S. Nakamura, Y. Sato, FUJIFILM Corp. (Japan); K. Ishii, The Graduate School for the Creation of New Photonics Industries (Japan) 
9232 0J Measurement of dispersion of nanoparticles in a dense suspension by high-sensitivity lowcoherence dynamic light scattering [9232-4]

K. Ishii, The Graduate School for the Creation of New Photonics Industries (Japan);

S. Nakamura, Y. Sato, FU JIFILM Corp. (Japan)

9232 OK On the size and morphological characterization of needle-shaped TiO2 nanoparticles in suspension [9232-32]

F. A. Onofri, C. Pelcé, L. Meister, Institut Univ. des Systèmes Thermiques Industriels, CNRS, AixMarseille Univ. (France); C. Montet, Institut Univ. des Systèmes Thermiques Industriels, CNRS, Aix-Marseille Univ. (France) and CILAS (France); P. Pelcé, Institut de Recherche sur les Phénomènes Hors Équilibre, CNRS, Aix-Marseille Univ. (France); S. Barbosa, M. Sentis, Institut Univ. des Systèmes Thermiques Industriels, CNRS, Aix-Marseille Univ. (France); M. Bizi, BRGM (France)

9232 OL Recent activity of international comparison for nanoparticle size measurement [9232-13] K. Takahashi, K. Takahata, I. Misumi, K. Sugawara, S. Gonda, K. Ehara, National Institute of Advanced Industrial Science and Technology (Japan)

$92320 \mathrm{M}$ Single nanoparticle imaging method based on photothermal effect by use of single element interferometer [9232-33]

Y. Nagata, Y. Mizutani, T. Iwata, Univ. of Tokushima (Japan); Y. Otani, Utsunomiya Univ. (Japan)

\section{AEROSOLS AND ENVIRONMENTAL MONITORING}

9232 ON Aerosol characterization with lidar methods [9232-43]

N. Sugimoto, T. Nishizawa, A. Shimizu, I. Matsui, National Institute for Environmental Studies (Japan)

923200 Flow visualization of a non-contact transport device by Coanda effect [9232-36]

N. Iki, H. Abe, T. Okada, National Institute of Advanced Industrial Science and Technology (Japan)

9232 OP Measurement of aerosol hydration states using the EDB coupled to a Raman spectrometer [9232-8]

Y. Ishizaka, A. Harano, Gunma Univ. (Japan)

$92320 Q \quad$ New apparatus of single particle trap system for aerosol visualization [9232-21]

H. Higashi, Kanazawa Univ. (Japan); T. Fujioka, T. Endo, Taisei Corp. (Japan); C. Kitayama, T. Seto, Y. Otani, Kanazawa Univ. (Japan)

9232 OR Offshore wind profile measurements using a Doppler LIDAR at the Hazaki Oceanographical Research Station [9232-5]

S. Shimada, National Institute of Advanced Industrial Science and Technology (Japan); T. Ohsawa, Kobe Univ. (Japan); T. Ohgishi, Y. Kikushima, T. Kogaki, National Institute of Advanced Industrial Science and Technology (Japan); K. Kawaguchi, S. Nakamura, PARI (Japan) 
9232 OS Measurement and identification of ultrafine bubbles by resonant mass measurement method [9232-42]

H. Kobayashi, S. Maeda, M. Kashiwa, T. Fujita, IDEC Corp. (Japan)

9232 OT Measurement of the change in the number of ultrafine bubbles through pressurization [9232-7]

T. Tuziuti, K. Yasui, W. Kanematsu, National Institute of Advanced Industrial Science and Technology (Japan)

9232 OU Measurements of ultrafine bubbles using different types of particle size measuring instruments [9232-37]

H. Kobayashi, S. Maeda, M. Kashiwa, T. Fujita, IDEC Corp. (Japan)

$9232 \mathrm{OV}$ The effect of dilution on the quantitative measurement of bubbles in high-density ultrafine bubble-filled water using the light scattering method [9232-41]

S. Maeda, H. Kobayashi, K. Ida, M. Kashiwa, I. Nishihara, T. Fujita, IDEC Corp. (Japan)

\section{BIOMEDICAL APPLICATIONS}

$9232 \mathrm{OW} \quad$ Estimation of trapping position in three-dimensional off-axis trapping with optical vortices [9232-48]

T. Ando, T. Ołsu, Y. Takiguchi, Y. Ohtake, H. Toyoda, H. Itoh, Hamamatsu Photonics K.K. (Japan)

$92320 \mathrm{X}$ Optical characterization of facial foundation applied to skin replicas by using visible FFOCT [9232-30]

R. Kimura, T. Iwai, Tokyo Univ. of Agriculture and Technology (Japan); T. Tsugita, KAO Corp. (Japan)

9232 OY Topological imaging of blood vessels by using diffusing light [9232-27]

S. Kohama, T. Iwai, Tokyo Univ. of Agriculture and Technology (Japan)

\section{CONTEMPORARY ISSUES}

$92320 Z$ Energy transfer mechanisms in green emitting LiBaPO4:Tb3+ phosphors [9232-45]

R. Yang, National Pingtung Univ. of Science and Technology (Taiwan); H. Lai, Y. Peng,

S. Chang, National Cheng Kung Univ. (Taiwan)

923210 Laser diffraction of acicular particles: practical applications [9232-49]

D. M. Scott, DuPont Co. (United States) and Scott Applied Research (United States);

T. Matsuyama, Soka Univ. (Japan) 
923211 Optical measurement method for particles on printed substrate by light-scattering [9232-35]

K. Shibakiri, S. Fujii, N. Kagi, Tokyo Institute of Technology (Japan)

Author Index

Proc. of SPIE Vol. $9232923201-7$

Downloaded From: https://www.spiedigitallibrary.org/conference-proceedings-of-spie on 26 Apr 2023 Terms of Use: https://www.spiedigitallibrary.org/terms-of-use 
Proc. of SPIE Vol. $9232923201-8$

Downloaded From: https://www.spiedigitallibrary.org/conference-proceedings-of-spie on 26 Apr 2023 Terms of Use: https://www.spiedigitallibrary.org/terms-of-use 


\title{
Conference Committee
}

\author{
Conference Chair
}

Nobuhiro Aya, AIST (Japan)

Steering Committee

Nobuhiro Aya, AIST (Japan)

Kensei Ehara, AIST (Japan)

Shigehisa Endoh, Technology Research Association for Single Wall Carbon Nanotubes (Japan)

Hirohide Furutani, AIST (Japan)

Naoya Hama, Tokyo Dylec Corporation (Japan)

Tatsuo Igushi, HORIBA, Ltd. (Japan)

Norihiko Iki, AIST (Japan)

Katsuhiro Ishii, Graduate School for the Creation of New Photonics Industries (Japan)

Wuled Lenggoro, Tokyo University of Agriculture and Technology

(Japan)

Tatsushi Matsuyama, Soka University (Japan)

Atsushi Nukanobu, Nikkiso Company, Ltd. (Japan)

Norikazu Namiki, Kogakuin University (Japan)

Tsutomu Shimura, The University of Tokyo (Japan)

Tomohiro Shirai, AIST (Japan)

Kayori Takahashi, AIST (Japan)

Jack Yamada, Galileo, Inc. (Japan)

Program Committee

Toshimitsu Asakura, Hokkaido University (Japan)

Nobuhiro Aya, AIST (Japan)

William D. Bachalo, Atrium Technologies Inc. (United States)

Hirotsugu Fujita, Kobe University (Japan)

Otto Glatter, Karl-Franzens-Universität Graz (Austria)

Leon Gradon, Warsaw University of Technology (Poland)

Nohiriko Iki, AIST (Japan)

Toshiaki Iwai, Tokyo University of Agriculture and Technology (Japan)

Isao Kataoka, Osaka University (Japan)

Tatsuya Kawaguchi, Tokyo Institute of Technology (Japan)

Masanobu Maeda, Keio University (Japan)

Hirokata Oku, Ministry of Education, Culture, Sports, Science and Technology (Japan) 
Kikuo Okuyama, Hiroshima University (Japan)

Tsutomu Shimura, The University of Tokyo (Japan)

Tomoriho Shirai, AIST (Japan)

Susumu Tohno, Kyoto University (Japan)

Kuniko Urashima, NISTEP, Ministry of Education (Japan)

Paul E. Wagner, Universität Wien (Austria)

Toyohiko Yatagai, Utsunomiya University (Japan)

International Advisory Committee

Choongsik Bae, KAIST (Korea, Republic of)

Meng-Dawn Cheng, Oak Ridge National Laboratory (United States)

Toshiaki Iwai, Tokyo University of Agriculture and Technology (Japan)

Alfred Leipertz, Friedrich-Alexander-Universität Erlangen-Nürnberg

(Germany)

Fabrice Lemoine, Université de Lorraine (France)

Ta-Hui Lin, National Cheng Kung University (Taiwan)

James A. Lock, Cleveland State University (United States)

Xandra Margot, Universitat Politècnica de València (Spain)

Yoshio Otani, Kanazawa University (Japan)

Greg Smallwood, National Research Council Canada (Canada)

Alex M. K. P. Taylor, Imperial College (United Kingdom)

Cameron Tropea, Technische Universität Darmstadt (Germany)

Ken-ichi Ueda, University of Electro-Communications (Japan)

Bianca Maria Vaglieco, Istituto Motori, CNR (Italy)

Satoshi Wada, RIKEN (Japan)

Paul E. Wagner, Universität Wien (Austria)

Masanobu Watanabe, AIST (Japan)

Yuyin Zhang, Shanghai Jiao Tong University (China)

\section{Session Chairs}

1 Spray/Droplet

Choongsik Bae, KAIST (Korea, Republic of)

2 Droplet/Combustion

Ta-Hui Lin, National Cheng Kung University (Taiwan)

Takashi Suzuki, Toyohashi University of Technology (Japan)

3 Droplet

Yuyin Zhang, Shanghai Jiao Tong University (China)

Takashi Suzuki, Toyohashi University of Technology (Japan) 
Denis Koltsov, BREC Solutions Ltd. (United Kingdom)

Nobuhiro Aya, AIST (Japan)

5 Simulation

Fabrice Onofri, CNRS, Aix-Marseille Université (France)

Katsuhiro Ishii, Graduate School for the Creation of New Photonics Industries (Japan)

6 Droplet II

Norihiko Iki, AIST (Japan)

7 Diffraction Method

Tatsushi Matsuyama, Soka University (Japan)

Makoto Umezawa, HORIBA Ltd. (Japan)

8 Flow/Environment Monitoring

William D. Bachalo, Atrium Technologies Inc. (United States)

Shigehisa Endoh, Technology Research Association for Single Wall Carbon Nanotubes (Japan)

$9 \quad$ Nucleation and Growth

Paul E. Wagner, Universität Wien (Austria)

Masayuki Itoh Doshisha University (Japan)

10 Contemporary Issues

Tsutomu Shimura, The University of Tokyo (Japan)

11 Low-coherence DLS

Frank Scheffold, University of Fribourg (Switzerland)

Toshiaki Iwai, Tokyo University of Agriculture and Technology (Japan)

12 Aerosols

Norikazu Namiki, Kogakuin University (Japan)

13 Surface

Kayori Takahashi, AIST (Japan)

$14 \quad$ Trapping

Tsutomu Shimura, The University of Tokyo (Japan)

15 Nanoparticle

Wuled Lenggoro, Tokyo University of Agriculture and Technology (Japan)

Katsuhiro Ishii, Graduate School for the Creation of New Photonics Industries (Japan) 
Proc. of SPIE Vol. 9232 923201-12

Downloaded From: https://www.spiedigitallibrary.org/conference-proceedings-of-spie on 26 Apr 2023 Terms of Use: https://www.spiedigitallibrary.org/terms-of-use 


\section{Introduction}

There are continuing and growing needs for techniques to determine the behaviors and characteristics of particles and the developments of nanomaterials in science, engineering, medicine, human-environment, and leading industries. Optical methods are the most powerful tools, and they are capable of rapid on-line and in-situ measurement of various sizes of particles and their behaviors from molecular clusters to raindrops.

The International Conference on Optical Particle Characterization (OPC 2014) was held 10-14 March 2014 at the AIST Tokyo Waterfront, Tokyo, Japan, in order to discuss not only the optical measurement of particle concentration, size, shape, structure, and composition in various phases, but also the optical handling of particulate matter with the traditional and novel methods. It was the 10th international scientific conference which aims to contribute to development of the whole science and technology on the particle characterization with light, succeeding the basic principle of the previous successful series of conferences on OPC (and OPS = Optical Particle Sizing-the former name of the conference series) since 1987.

Forty-six oral presentations were accepted and made in 15 sessions at OPC 2014. Five invited lectures were given by the following leading scientists who were recommended by the international advisory committee and the program committee of OPC2014, viz., Dr. W. Bachalo, Atrium Technologies Inc. (United States), Prof. F. Scheffold, University of Fribourg (Switzerland), Prof. M. Shibayama, The University of Tokyo (Japan), Prof. P. Wagner, University of Vienna (Austria), and Prof. Y. Zhang, Shanghai Jiao Tong University (China). Also, Dr. D. Koltsov, BREC Solutions Ltd. (United Kingdom), gave a special lecture titled "Nanomaterials and fine bubbles standardisation and regulation" at the joint workshop of OPC2014, AIST, and FBIA (Fine Bubble Industry Association) held on the opening day of OPC2014.

Very fruifful discussions were made at OPC 2014. The conference program covered theoretical and experimental works, pertaining to the fundamentals of optical particle sizing and characterization, as well as its scientific, technological, and industrial applications.

In this proceeding volume, 36 original papers are published from among the studies presented at OPC 2014 after a post-conference peer reviewing process 
coordinated by the scientists on each field including the chairs of the sessions and the committee members. Two of the invited papers are also included.

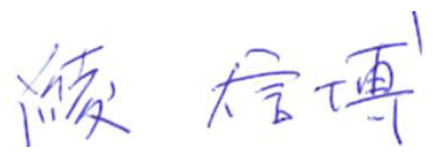

Nobuhiro Aya 